\section{$\underset{\substack{\text { hommes } \\ \text { \& migrations }}}{ }$}

\section{Hommes \& migrations}

Revue française de référence sur les dynamiques

migratoires

$1306 \mid 2014$

Ecriture et migration

\title{
Isabelle Condou, Un pays qui n'avait pas de port,
}

Paris, Plon, 2013, 305 pages, $18 €$.

\section{Michaël Ferrier}

\section{(2) OpenEdition \\ 1 Journals}

\section{Édition électronique}

URL : http://journals.openedition.org/hommesmigrations/2820

DOI : $10.4000 /$ hommesmigrations.2820

ISSN : 2262-3353

\section{Éditeur}

Musée national de l'histoire de l'immigration

\section{Édition imprimée}

Date de publication : 1 avril 2014

Pagination : 115-115

ISBN : 978-2-919040-27-8

ISSN : $1142-852 X$

\section{Référence électronique}

Michaël Ferrier, «Isabelle Condou, Un pays qui n'avait pas de port, », Hommes \& migrations [En ligne],

1306 | 2014, mis en ligne le 06 août 2014, consulté le 22 septembre 2020. URL : http://

journals.openedition.org/hommesmigrations/2820 ; DOI : https://doi.org/10.4000/

hommesmigrations.2820

Ce document a été généré automatiquement le 22 septembre 2020.

Tous droits réservés 


\section{Isabelle Condou, Un pays qui n'avait pas de port,}

Paris, Plon, 2013, 305 pages, $18 €$.

Michaël Ferrier

\section{RÉFÉRENCE}

Isabelle Condou, Un pays qui n'avait pas de port,

Paris, Plon 2013, 305 pages, $18 €$.

\section{NOTE DE L'ÉDITEUR}

Sélection 2014 de la $5^{e}$ édition du prix littéraire de la Porte Dorée

1 Le sujet est original : voir le thème si large de la migration sous un éclairage bien précis, celui d'une traversée au long cours et de la découverte d'un passager clandestin, qui va faire réagir trois personnages du cargo - le capitaine Bohdan, l'officier Marek et la passagère Joséphine - chacun à sa manière.

2 La langue d'Isabelle Condou est précise, les phrases bien tournées, un brin précieuses. Les analyses psychologiques sont fines, surtout lorsqu'il s'agit de la vie maritime ("cette curiosité avide de percer un mystère que montraient toujours les passagers à bord d'un cargo", ou cette brève mais éloquente description de la vie du marin: "une vie d'homme, seul parmi des hommes seuls, les yeux tendus sur l'horizon avec tantôt l'espoir et tantôt la crainte qu'une aspérité s'y dessine").

3 Au fil du récit - comme on dirait au fil de l'eau -, plusieurs histoires émergent : sur l'océan, une baleine fait surgir une histoire, des souvenirs d'enfance s'élèvent au simple son d'une voix... Isabelle Condou sait nouer habilement les thèmes de la navigation et de la remémoration. C'est l'exil qui forme la trame du livre, et revient à plusieurs reprises dans ces écumes de la réminiscence. En deux anecdotes, l'auteure nous en dit 
énormément sur l'importance de la langue, des rapports complexes entre la nomination et la mémoire sur les chemins de l'exil. Il s'agit des réflexions sur les noms des personnages, "l'épouvante de la lettre $K$ " par exemple, qui signe l'appartenance à la communauté maudite des exilés polonais (Marek, Kraków... "Le fameux K, synonyme de Polak" !), ou de l'histoire - absurde et cuisante - du curé qui ne se souvient plus du nom de l'étranger quand il faut le prononcer lors de son enterrement...

4 Sont-ce les paragraphes qui se succèdent, tous à peu près de même taille (plutôt longs)? Ou le style de temps en temps un peu trop corseté (ah, les subjonctifs imparfait...) ? Au fur et à mesure de cette traversée, le rythme du journal, avec son ordre chronologique sans surprise ( 21 février, 22 février...), et la composition très linéaire de l'ouvrage, qui sait si bien rendre la monotonie du voyage, pourront aussi susciter à la longue un peu de lassitude. Une autre question, qui est aussi un regret: pourquoi ne sait-on pratiquement rien de ce clandestin? Il n'est finalement que le support de la réaction des autres et passe dans le texte comme un fantôme... Mais sans doute est-ce la leçon même de ce livre : l'exilé est toujours l'absent, le fantôme, la forme en creux dont on ne retrouve le plus souvent, un beau matin, que les vêtements déchiquetés dans un train d'atterrissage ou une paire de chaussures sur le bastingage... Quoi qu'il en soit, le livre est beau, le titre est magnifique, les dernières pages poignantes. 